\title{
Capacidade relacional em alianças estratégicas de inovação: um ensaio teórico para o desenvolvimento de um modelo conceitual
}

\author{
Relational capacity in strategic alliances of \\ innovation: a theoretical study for the \\ development of a conceptual model
}

\author{
(19) Taísa Scariot Preusler ${ }^{1}$ \\ (D) Priscila Rezende da Costa² \\ (D) Tatiane Baseggio Crespi ${ }^{3}$
}

${ }^{1}$ Bacharel em Secretariado Executivo Bilíngue e Especialista em Economia e Gestão Empresarial pela Universidade de Passo Fundo, Mestre em Administração pelo programa Minter da Universidade Nove de de Julho (UNINOVE) e Instituto de Desenvolvimento Educacional (IDEAU). Gestora de contratos na Empresa Brasileira de Pesquisa Agropecuária - Embrapa. Passo Fundo, Rio Grande do Sul, Brasil. taisa.s@hotmail.com

${ }^{2}$ Bacharel, Mestre e Doutora em Administração. Atualmente é professora e coordenadora no Programa de Pós-graduação em Administração, Mestrado e Doutorado da Universidade Nove de Julho, UNINOVE. São Paulo, SP. priscilarc@uninove.br

${ }^{3}$ Mestre em Administração pelo programa Minter da Universidade Nove de de Julho (UNINOVE) e Instituto de Desenvolvimento Educacional (IDEAU), Especialista em

Genética e Evolução Biológica e Bacharel em Ciências Biológicas pela Universidade de Passo Fundo. Analista na Empresa Brasileira de Pesquisa Agropecuária - Embrapa. Passo Fundo, Rio Grande do Sul, Brasil. tatianebseggiocrespi@gmail.com

\section{Resumo}

É desafiador realizar pesquisa e desenvolvimento (P\&D) internamente e de forma isolada, em função da demanda de altos recursos financeiros e conhecimentos. Assim, a formação de alianças estratégicas é uma alternativa capaz de propiciar à organização uma complementação da sua base de recursos. No entanto, seu desempenho depende da capacidade relacional, isto é, de um conjunto de rotinas e processos estabelecidos para gerenciar e criar valor a partir da interação estabelecida. Neste artigo tem-se como objetivo desenvolver um modelo conceitual de geração de inovações no contexto de alianças estratégicas por meio da capacidade relacional. Para tanto, realizou-se um ensaio teórico de natureza exploratória mediante revisão bibliográfica. Por fim, são apresentadas contribuições ao campo conceitual da capacidade relacional, envolvendo proposições de pesquisa sobre a formação de alianças estratégicas com instituições distintas (de maior ou menor conexão com o mercado) e também sobre os múltiplos objetivos das alianças (para pesquisa ou desenvolvimento)

Palavras-chave: P\&D. Inovação. Alianças estratégicas. Capacidade relacional.

\section{Abstract}

It is challenging to conduct research and development (R \& D) internally and in isolation, due to high financial resources and knowledge demand. Thus, strategic alliances formation is an alternative to provide resource base complementation to an organization. However, their performance depends on the relational capacity, that is, on a set of established routines and processes to manage and create value from the established interaction. This article aims to develop an innovation generation conceptual model in strategic alliances context through relational capacity. For that, a theoretical essay of exploratory nature was carried out by means of a bibliographic review. Finally, contributions are presented to relational capacity conceptual field, involving research propositions about the formation of strategic alliances with different institutions (of greater or lesser connection with the market) and also about the multiple objectives of the alliances (for research or development).

Palavras-chave: R\&D. Innovation. Strategic aliances. Relational capacity. 
Introdução

Diante de um mundo globalizado, o progresso de uma instituição, comunidade, empresa ou país está diretamente relacionado à capacidade de gerar inovações. Novos conhecimentos, produtos, processos, métodos, assim como o aperfeiçoamento dos já existentes, devem ser trazidos ao mercado com grande rapidez, fexibilidade e confiabilidade (Feller, Parhankangas, Smeds, \& Jaatinen, 2013). Em decorrência da dificuldade de promover, isoladamente, as mencionadas inovações, as alianças estratégicas têm sido consideradas uma alternativa, nas últimas décadas, às instituições, para a realização de P\&D para a geração de inovação, haja vista a possibilidade de complementação de recursos (Dyer \& Singh, 1998), acesso a novos mercados e redução de custos (Ahuja, 2000). Essas podem ser formadas entre atores de diferentes natureza, como universidades, empresas privadas, públicas, concorrentes, clientes, fornecedores, institutos de pesquisa público ou privados (Möller \& Halinen, 1999).

O desempenho da alianças, todavia, dependerá da capacidade da instituição organização em adquirir habilidades, trocar continuamente informações e aprendizados, criar estruturas e gerenciar conflitos, o que estabelecerá a confiança mútua entre as partes e, por conseguinte, a geração de valor (Yan, Zhang, \& Zeng, 2010), denominada capacidade relacional (CR). A CR é formada por uma construção multidimensional, baseada em rotinas e processos corporativos, dividida em cinco dimensões: coordenação interorganizacional, transformação da aliança, aprendizagem interorganizacional, proatividade em alianças e portfólio de alianças, influenciado por dois fatores: a experiência e a estrutura de governança (Schilke \& Goerzen, 2010).

Tendo em vista a relevância desta temática, busca-se neste artigo desenvolver um modelo conceitual de geração de inovações no contexto de alianças estratégicas por meio da capacidade relacional. Para tal, é realizado ensaio teórico de natureza exploratória mediante revisão bibliográfica. Como contribuições à literatura são apresentadas proposições de pesquisa e descrito um modelo conceitual sobre a formação de alianças estratégicas com instituições distintas (de maior ou menor conexão com o mercado) e também sobre os múltiplos objetivos das alianças (para pesquisa ou desenvolvimento) potencializando desta forma, o desenvolvimento de futuros estudos empíricos sobre inovação, alianças estratégicas e capacidade relacional.

\section{Abordagem metodológica}

Trata-se de um ensaio teórico de natureza exploratória, por meio de uma revisão bibliográfica em que se busca o aperfeiçoamento de ideias (Gil, 2002). O desenvolvimento desse estudo foi motivado pelo anseio em avaliar de forma crítica, como o desenvolvimento da capacidade relacional pode 
contribuir para a geração de inovações desenvolvidas no contexto de alianças estratégicas, sendo assim desenvolvido um modelo interligado às concepções apresentadas no referencial teórico.

Este estudo apresenta como as principais lentes teóricas, inovação, alianças estratégicas e capacidade relacional. A inovação é interpretada com base na Economia Evolucionária Neoschumpeteriana e é considerada um processo dependente, em que o conhecimento e a tecnologia são desenvolvidos pela interação entre vários atores (Winter \& Nelson, 1982). As alianças estratégicas e capacidade relacional são analisadas a partir da perspectiva da Visão Baseada em Recursos (VBR) (Barney, 1991; Teece et al., 1997). Para cada teoria buscou-se conceitos de estudos seminais e de mais atual para a elaboração do modelo.

\section{Fundamentação teórica}

O mercado tem sido cada vez mais impactado por rápidas mudanças tecnológicas, grande variedade de produtos e exigência de alto nível de especialização (Hitt, Ireland, \& Lee, 2000). A alta velocidade influencia o processo produtivo, reduzindo o ciclo de vida dos produtos e, consequentemente, o tempo que as empresas têm para a recuperação de seus investimentos (Narula \& Hagedoorn, 1999). Nesse contexto, a inovação é considerada como uma ferramenta essencial para aumentar a demanda por produtos e serviços, reduzir custos (OCDE, 2005) e ainda, melhorar o desempenho competitivo no mercado (Ireland \& Webb, 2007).

Entre as diversas definições para inovação, na literatura, está o conceito mais clássico e disseminado, apresentado na obra seminal de Shumpeter (1934), que a trata como o ato de desenvolver novos produtos, utilizar tipos diferentes de materiais ou artigos intermediários, criando, explorando ou reorganizando o mercado. As inovações ainda podem ser diferenciadas em quatro tipos, de acordo com o Manual de Oslo (2005): inovação de processo, produto, marketing e organizacional.

Historicamente, verifica-se que as empresas desenvolviam P\&D para a geração de inovações por meio da integração vertical, com fins de criação de seus próprios produtos, fazendo, posterioremente, sua distribuição (Chesbrough, 2006). Essa forma de atuação, todavia, foi se tornando mais difícil, em razão da complexidade dos produtos e do alto valor de investimento exigido para manter as capacidades técnicas necessárias ao seu lançamento no mercado (Philbin, Jones, Brandon, \& Hawkes, 2014).

Assim, a saída tem sido a busca de canais externos para a obtenção ou geração de inovação. Etzkowitz (2003) apresenta três diferentes soluções: fonte de informação aberta, que fornece informações sem que haja a obrigatoriedade de aquisão de tecnologia, pagamento de direitos de propriedade ou interação (OCDE, 2005); aquisição de tecnologia e conhecimento externo, na forma de mercadorias (softwares, maquinários e equipamentos) e de serviços (contratação de pessoas detentoras do conhecimento, contratos de pesquisa e consultoria) (OCDE, 2005); e por fim, a chamada 
inovação aberta (Freitas, Marques, \& Silva, 2013), em que se busca conhecimento e recursos externos para desenvolvimento de P\&D (Chesbrough, 2006). Assim, em muitos casos são formadas alianças estratégicas para o alcance dos objetivos.

A literatura apresenta que as alianças estratégicas têm sido consideradas pelas empresas como uma alternativa para encontrar ideias inovadoras e lucrativas (Jap, 2001), reduzir custos, ter acesso a novos mercados (Ding et al., 2013), novas tecnologias, know-how, compartilhamento de incertezas e riscos com parceiros (Powell, 1987).

Kale, Dyer e Singh (2002, p. 748) definem alianças estratégicas como "ligações entre as empresas iniciadas de forma independente que envolvem intercâmbio, partilha, ou co-desenvolvimento de tecnologias, produtos ou serviços". As alianças estratégicas podem ser analisadas a partir de diferentes teorias, dentre as quais, a da Visão Baseada em Recurso (VBR) e a institucional.

A VBR postula que, entre as principais motivações que levam à formação de alianças estratégicas, está a possibilidade de as empresas conquistarem vantagens competitivas, por meio do acesso a recursos idiossincráticos dos parceiros ou pelo desenvolvimento de competências (Barney, 1991) tácitas (Das \& Teng, 2000). Os recursos podem ser divididos entre tangíveis, quando se tratam de recursos financeiros e físicos; intangíveis, que abrangem tecnologia, reputação e recursos organizacionais; e por fim, humanos, que estão relacionados às especialidades dos empregados, treinamento e cultura (Grant, 1991). Outra motivação é a possibilidade de aumento da aprendizagem organizacional, o que leva ao desenvolvimento de conhecimentos críticos e diversificados, por meio de novas ideias ou diferentes formas de realizar negócios (Gulati, 1998; Hamel, 1991).

A teoria institucional fundamenta que a formação de alianças estratégicas se dá a partir de pressões exercidas por uma organização sobre outras das quais dependem, ou por expectativas culturais, a fim de que regras, normas e valores similares sejam adotados dentro de um cenário comum (DiMaggio \& Powell, 1983), havendo a aquisição de legitimidade social e o aumento das chances de permanência ativa no mercado (Meyer \& Rowan, 1977). Nesse sentido, alianças podem ser formadas com o objetivo de atender às pressões que surgem a partir: a) do sistema regulatório: pressões para que as empresas sigam regras, regulamentos e normas (Oliver, 1991); b) das normas da indústria: pressões que empresas ou concorrentes de um mesmo setor exercem sobre outras empresas, para que busquem o aperfeiçoamento de suas operações; ou a exigência da adoção de códigos ou padrões regulatórios, de modo a tornar a indústria mais legítima (Etzion, 2007); c) grupos da comunidade motivados por pressões exercidas por ONGs ambientais e grupos sociais, em função da preocupação com o aumento da destruição ambiental (ativismo e ações judiciais) (Delmas \& Toffel, 2004).

A partir do estudo de alianças voltadas a problemas ambientais complexos, Lin e Darnall (2015) desenvolveram um framework para apresentar diferentes estruturas, formadas de acordo com a orientação (baseadas na competência e na legitimidade) e as dimensões da aliança: aprendizagem 
organizacional (explorative e exploitative), diversidade de parceiros (heterogêneo e homogêneo), estrutura de governança (não representada e representada) e relacionamento com parceiros (laços fortes e laços fracos), conforme apresentado na Figura 1.

Figura 1 - Relações entre orientação da aliança e estrutura

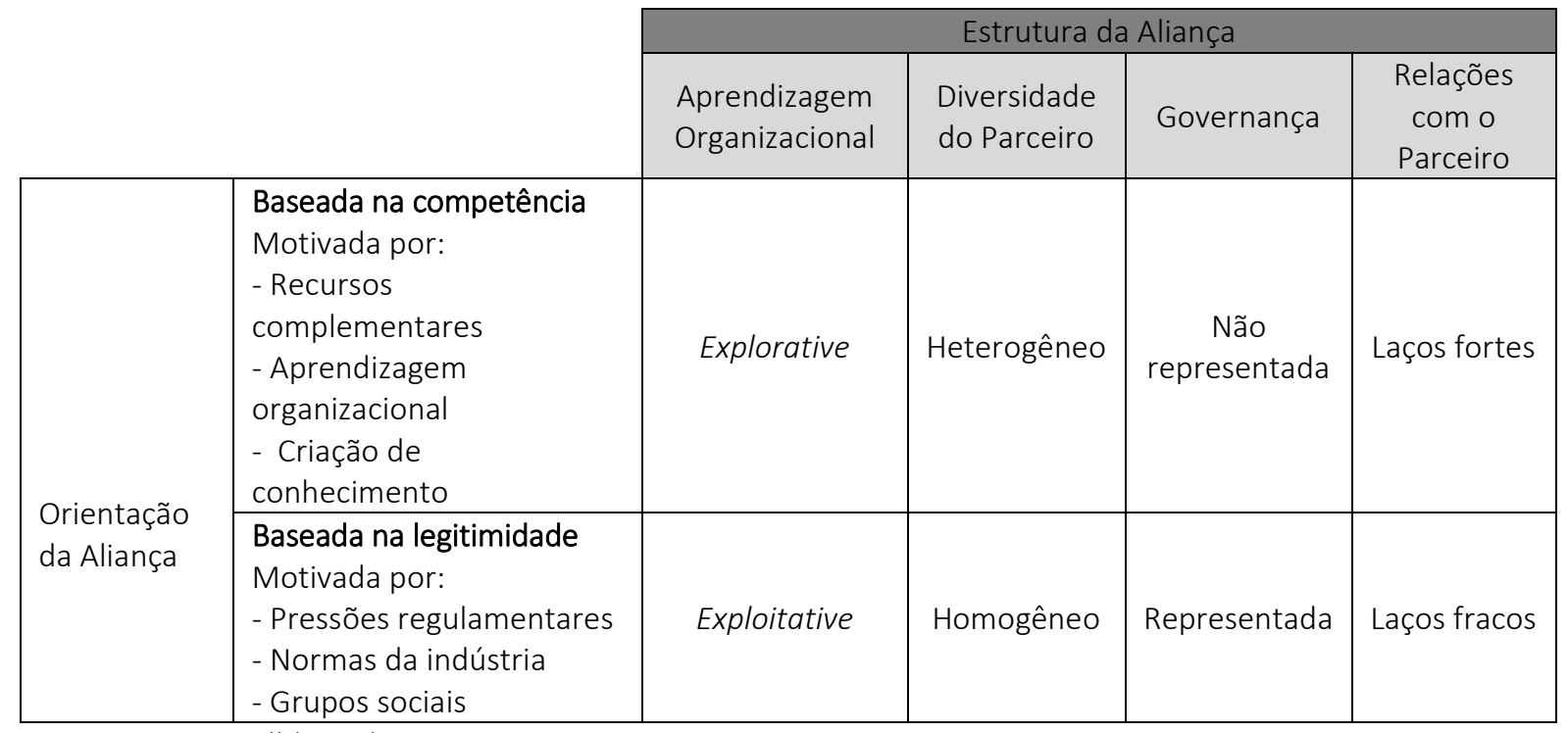

Fonte: Lin e Darnall (2015).

Alianças orientadas para competência são fundamentadas pela VBR e motivadas pelo desejo que as empresas têm de aprimorar seus recursos internos (pelo acesso a recursos complementares) e o conhecimento interno (pela aprendizagem organizacional e criação de conhecimento) (Lin \& Darnall, 2015). Por outro lado, alianças baseadas na legitimidade buscam atender às pressões exercidas (regulatórias, industriais e grupos comunitários), com o objetivo de aumentarem suas chances de sobrevivência, com foco na teoria institucional (Dacin, Oliver, \& Roy, 2007).

A aprendizagem da organização pode ser categorizada em dois tipos de exploração, exploration e exploitation. A exploration está relacionada a um tipo de aprendizado que visa ao desenvolvimento de novas oportunidades (Koza \& Lewin, 1998; Rothaermel \& Deeds, 2004), estimulando mudanças comportamentais significativas, por meio de riscos, novas descobertas, experimentação, flexibilidade (March, 1991), levando a mudanças profundas, radicais e transformadoras (Etzion, 2007). Esse tipo de aprendizagem é mais utilizado por alianças orientadas para a competência, uma vez que, por meio da percepção da incerteza e da imprevisibilidade, busca-se reunir recursos para desenvolver novas competências. Esse tipo de aliança envolve mais riscos de longo prazo (Lin, Yang, \& Demirkan, 2007; Park, Chen, \& Gallagher, 2002), e o resultado leva ao desenvolvimento de novos produtos e serviços, de inovações radicais e da inserção em novos mercados (Etzion, 2007). 
A exploitation visa ao aprimoramento de uma capacidade existente (Koza \& Lewin, 1998; Rothaermel \& Deeds, 2004) buscando, por meio de mudanças incrementais (March, 1991), aperfeiçoamento das atividades empresariais, refinamento, padrões de atuação e rotinas, a fim de reduzir riscos e custos e aumentar as chances de sobrevivência. Esse tipo de aliança é formado por empresas que têm o intuito de comercializar suas tecnologias e de, por meio de licenciamento, disseminar modelos bem-sucedidos e práticas (Barringer \& Harrison, 2000). São, portanto, alianças motivadas pela legitimidade.

Alianças orientadas para a competência são mais suscetíveis a buscar parceiros heterogêneos (empresas, universidades, institutos de pesquisa, fornecedores e clientes) e intersetoriais (instituto de pesquisa público com a indústria) ou fornecedores e clientes (Walsh, Lee, \& Nagaoka, 2016). A diversidade de parceiros, em que cada um possui uma especialização única e variada e diferentes configurações de parcerias, contribui para que as empresas consigam agregar ativos, capacidades e habilidades distintas e complementares (Lin \& Darnall, 2015; Powell, Koput, \& Smith-Doerr, 1996), e evita a sobreposição de competências (Darnall \& Edwards, 2006). Quando se formam alianças com organizações não conectadas ao mercado, cujo objetivo principal não é a lucratividade, mas a preocupação com o bem-estar da sociedade (Darnall \& Edwards, 2006), os gestores são levados a conduzirem a aprendizagem organizacional de ordem superior (Christmann, 2000), com a finalidade de aguçar a percepção de novas oportunidades de negócios, bem como de ampliar a aprendizagem e o desenvolvimento de inovações radicais (Lin \& Darnall, 2015).

Por outro lado, empresas cuja motivação é voltada para a legitimidade, tendem a buscar parceiros menos diversificados dentro da própria indústria, visando melhorar sua posição e defender regulamentos ou padrões não tão rigorosos, remodelando o contexto regulatório em favor das práticas existentes (Oliver, 1991). Juntando-se a parceiros mais homogêneos conseguem "enfrentar as pressões externas para melhorar a imagem da indústria, reputação e posição estratégica, e simultaneamente replicar negócios das empresas atuais, que por sua vez, melhora suas chances de sobrevivência" (Lin \& Darnall, 2015, p.557).

A terceira dimensão estrutural, que diferencia as alianças estratégicas está relacionada às estruturas de governança e aos mecanismos contratuais que regem as alianças (Kok \& Creemers, 2008). As mesmas diferenciam-se entre representadas e não representadas. Estruturas não representadas são menos articuladas, demandam pouca formalidade e propriedade conjunta (Dacin et al., 2007; Gulati, 1995a, 1995b). Esse tipo de estrutura é mais utilizada por alianças baseadas na competência, pois, por meio de maior flexibilidade contratual, há a possibilidade da readequação da aliança, à medida que novas ideias vão surgindo ou sendo aprimoradas (Kok \& Creemers, 2008; Koza \& Lewin, 1998), e maior engajamento com o desenvolvimento de inovações e novos modelos de negócios (Lin \& Darnall, 2015). 
Em contrapartida, nas estruturas de representatividade, os participantes estão ligados por estruturas mais formais e envolvem, muitas vezes, a propriedade conjunta (Dacin et al., 2007). Esse tipo de estrutura é utilizado, em sua maioria, por alianças baseadas na legitimidade, presentes, principalmente, no setor manufatureiro (Kogut, 1988). Acordos mais regrados e formais desencadeiam maior nível de confiança entre os parceiros para compartilhar informações de processos, produtos e competências existentes (Koza \& Lewin, 1998). Embora seja menos flexível, dificultando o processo criativo na tomada de decisão, a estrutura de representatividade é essencial para conseguir coordenar a aliança e expandir as competências e produtos existentes (Kok \& Creemers, 2008).

A última dimensão estrutural que diferencia as alianças são as relações com os parceiros, caracterizadas pela força dos laços, que podem ser fortes ou fracos. Para Granovetter (1973), a força dos laços pode ser determinada pelo tempo que as organizações dedicam para alcançar as metas e os objetivos da aliança, pela prestação de serviços recíprocos e, pelo nível de intimidade e confiança estabelecido entre os parceiros. Laços fortes estão presentes, principalmente, em alianças baseadas na competência, pela necessidade de encontrar e desenvolver alternativas mais inovadoras. Quando os laços são fortes, há maior interação entre as partes, aumentando a confiança, o compromisso mútuo e as normas (Ostrom, 1998), fazendo com que os parceiros estejam mais propensos à assunção de riscos e tenham menos receio de oportunismo (Ring \& Van de Ven, 1992). Há, também, maior propensão à transferência de conhecimento tácito entre as partes e à aprendizagem organizacional (Granovetter, 1973).

Os laços fracos são geralmente encontrados em alianças baseadas na legitimidade, uma vez que as relações não são tão intensas entre os parceiros, o que não desencadeia alto nível de confiança (Gulati, 1995a). Além disso, o objetivo maior desse tipo de aliança é aumentar a credibilidade e a legitimidade, atendendo às regras e normas do setor. Como as informações surgem de forma mais explícita, é mais fácil imitar planos bem-sucedidos, não havendo necessidade de formar laços fortes para compreender e alcançar os objetivos (Lin \& Darnall, 2015).

Lin e Darnall (2015) sugerem que alianças baseadas na competência são usualmente identificadas pelo aprendizado exploration, por possuírem parceiros diversos, estrutura de governança não representada e laços fortes na relação de parceria. Por outro lado, alianças baseadas na legitimidade se caracterizam, normalmente, pela aprendizagem exploitation, com parceiros similares, estruturas de governança de representatividade e relações de laços fracos.

Há diferentes tipos de alianças estratégicas, com distintas finalidades: para atividades P\&D, transferência de tecnologia, concessão de direitos de produção e vendas, cooperação em marketing etc. (Hagedoorn \& Narula, 1996). Podem, ainda, ser desenvolvidas com clientes, fornecedores e outros parceiros capazes de agregar valor; entre concorrentes (Möller \& Halinen, 1999) - empresas que atuam dentro da mesma indústria, com o intuito de desenvolver projetos de colaboração (Dussauge \& 
Garrette, 1995). Alianças podem ser formadas entre instituições de distinta natureza, como empresas que são mais conectadas com o mercado, que têm como objetivo desenvolver produtos de sucesso e instituições que têm em sua essência a geração e disseminação do conhecimento científico, ou seja, não são conectadas ao mercado (Cyert \& Goodman, 1997). As diferenças no foco e missão dessas instituições, fazem com que cada uma desenvolva recursos distintos (conhecimento do mercado e conhecimento científico), que na formação de uma aliança esses recursos se complementam e reforçam mutuamente (Wang \& Zajac, 2007).

Embora os benefícios da formação de parcerias verticais com fornecedores (Kalwani \& Narayandas, 1995) e clientes (Cannon \& Homburg, 2001) sejam inquestionáveis, os processos de cooperação horizontal, voltados à aprendizagem e P\&D (Powell et al., 1996), têm recebido maior destaque, haja vista seus benefícios, conhecidos como vantagens colaborativas (Donada, 2002) ou rendas relacionais, isto é, rendas resultantes de alianças interorganizacionais e que não podem ser geradas de forma independente (Dyer \& Singh, 1998).

Há quatro fontes de rendas relacionais identificadas (Dyer \& Singh, 1998). A primeira é o investimento em ativos específicos da relação, contribuindo para melhor coordenação e ajuste aos limites da empresa. Esse tipo de renda requer a alocação de recursos e processos orientados, tanto pelos parceiros, quanto pela empresa. Entre os recursos físicos específicos estão: equipamentos, softwares, pessoal e procedimentos (Dyer, 1997). A segunda renda diz respeito ao processo de gestão do conhecimento, isto é, à troca de conhecimentos substanciais, que resultam em aprendizagem. Ela é composta pela sequência de articulação, codificação, compartilhamento e internalização do conhecimento (Helfat et al., 2009). A terceira fonte é gerada quando as empresas desenvolvem a competência de combinar recursos escassos e capacidades, resultando na criação de novos produtos, serviços ou tecnologias. A operação, adaptação e gestão desses processos se dá de forma unificada, como se todas as empresas envolvidas na aliança representassem uma só (Rodríguez-Díaz \& EspinoRodríguez, 2006). A quarta fonte envolve custos de transação menores do que os dos concorrentes e suas alianças, conseguidos por intermédio de mecanismos de governança eficazes, que envolvem escolhas e mudanças necessárias às alianças (Jones, Hesterly, \& Borgatti, 1997). As rendas relacionais, no entanto, estão condicionadas ao êxito no alcance dos objetivos das alianças, pois sem este as mesmas não serão geradas.

A formação de alianças não é um processo simples, diversos estudos apontam alto índice de insucesso chegando a 60\% (Arino \& De La Torre, 1998), sendo oportuna a discussão sobre a capacidade de gestão das alianças estratégicas, nomeada de capacidade relacional.

Diferentes termos, com mesmo significado, são utilizados para definir o constructo da capacidade relacional. Alguns dos sinônimos encontrados na literatura são: capacidade de interação (Johnsen \& Ford, 2006), capacidade de aliança (Heimeriks \& Duysters, 2007; Kale et al., 2002; Pagano, 2009), 
capacidade de gestão de aliança (Niesten \& Jolink, 2015; Schilke \& Goerzen, 2010; Schreiner, Kale, \& Corsten, 2009), e colaboração interorganizacional (Yan et al., 2010).

Pontos de vista diferentes, mas complementares, de acordo com perspectivas distintas sobre as capacidades relacionais, estão exemplificados na Figura 2.

Figura 2 - Definição de capacidade relacional na perspectiva de diferentes autores

\begin{tabular}{|c|c|}
\hline Autores & Capacidade relacional \\
\hline $\begin{array}{l}\text { McGrath } \\
(2008)\end{array}$ & $\begin{array}{l}\text { Capacidade de gerenciar as atividades da aliança e conflitos; atuar de forma proativa com } \\
\text { outros atores, instigando a troca de informações e conhecimentos para aperfeiçoamento das } \\
\text { adaptações dos processos ou inovações; capacidade de internalizar os conhecimentos, } \\
\text { rotinas e recursos relevantes, acessados por meio da interação entre os parceiros. }\end{array}$ \\
\hline $\begin{array}{l}\text { Czakon } \\
(2009)\end{array}$ & $\begin{array}{l}\text { Criação proposital de arranjo de gestão e estrutura de governança, que possibilita a criação } \\
\text { de valor e aprendizagem entre dois ou mais atores, unindo recursos e explorando } \\
\text { capacidades, a fim de alcançar os objetivos dos parceiros. }\end{array}$ \\
\hline $\begin{array}{l}\text { Feller et al. } \\
\text { (2013) e } \\
\text { Schreiner et. } \\
\text { al. (2009) }\end{array}$ & $\begin{array}{l}\text { Habilidade que as empresas têm de adquirir, compartilhar, armazenar e aplicar o } \\
\text { conhecimento em gestão dessas alianças, como um importante antecedente para o } \\
\text { desempenho em alianças atuais ou futuras. }\end{array}$ \\
\hline Pagano (2009) & $\begin{array}{l}\text { Capacidade da empresa em gerenciar eficazmente seus relacionamentos, por meio de } \\
\text { recursos e atividades em prol da otimização de seu desempenho na aliança, utilizando } \\
\text { competências intra e interorganizacionais. }\end{array}$ \\
\hline $\begin{array}{l}\text { Heimeriks, } \\
\text { Klijn e Reuer } \\
(2009, \text { p. } 97)\end{array}$ & $\begin{array}{l}\text { "Capacidade da empresa em, adquirir, compartilhar, disseminar e aplicar o conhecimento da } \\
\text { aliança". }\end{array}$ \\
\hline $\begin{array}{l}\text { Capaldo e } \\
\text { Petruzelli } \\
\text { (2011, p. 274) }\end{array}$ & $\begin{array}{l}\text { "Capacidades interorganizacionais necessárias para que empresas juntas sejam capazes de } \\
\text { administrar recursos, capacidades e processos interorganizacionais, de forma que permita a } \\
\text { ambos parcerios gerar rendas relacionais e retorno apropriado". }\end{array}$ \\
\hline $\begin{array}{l}\text { Schilke e } \\
\text { Goerzen } \\
\text { (2010) }\end{array}$ & $\begin{array}{l}\text { Capacidade dinâmica que permite a aquisição de habilidade, troca de informações, } \\
\text { aprendizado constante com os parceiros, o que contribui para a criação de estruturas, o } \\
\text { gerenciamento de conflitos e a promoção da confiança para a geração de valor, aumentando, } \\
\text { com isso, a eficiência da aliança. }\end{array}$ \\
\hline $\begin{array}{l}\text { Delbufalo e } \\
\text { Cerruti (2012) }\end{array}$ & $\begin{array}{l}\text { Conjunto de rotinas que contribuem para a transferência de conhecimento entre parceiros; } \\
\text { capacidade de integração do conhecimento intra e interorganizacional para agilizar o acesso } \\
\text { ao conhecimento e de sua transferência, de forma a contribuir com o crescimento e inovação. }\end{array}$ \\
\hline $\begin{array}{l}\text { Costa, Porto e } \\
\text { Silva (2012) }\end{array}$ & Competências técnicas e interpessoais utilizadas no gerenciamento das parcerias. \\
\hline $\begin{array}{l}\text { Donada, } \\
\text { Nogatchewsky } \\
\text { e Pezet (2015, } \\
\text { p. } 3 \text { ) }\end{array}$ & $\begin{array}{l}\text { "Capacidade de integrar, construir e reconfigurar um conjunto de habilidades, ativos e rotinas } \\
\text { que fornecem os recursos base para lidar com a mudança de ambientes". }\end{array}$ \\
\hline $\begin{array}{l}\text { Alves (2015, } \\
\text { p.346) }\end{array}$ & $\begin{array}{l}\text { "Criação proposital e a combinação, a partir de recursos comuns, de estruturas intra e } \\
\text { interfirmas, tais como conhecimentos, rotinas, procedimentos e políticas, para o } \\
\text { desenvolvimento de atividades em conjunto, o gerenciamento de conflitos, a promoção de } \\
\text { confiança e a transferência de conhecimentos e informação, a fim de gerar valor e } \\
\text { aprendizagem entre as empresas e alcançar melhorias conjuntas de processo, adaptações } \\
\text { e/ou inovações em cooperações interorganizacionais". }\end{array}$ \\
\hline
\end{tabular}

Fonte: Dados da pesquisa.

A capacidade relacional tem sido considerada uma capacidade, que quando desenvolvida pelos parceiros, aumenta as chances de melhor desempenho das alianças com o propósito de contribuir para o alcance dos objetivos dos atores da aliança (Schilke \& Goerzen, 2010), 
garantindo o desempenho satisfatório entre eles (Yan et al., 2010). Ainda possibilita mais equilíbrio à formação de alianças e a proteção de ativos, uma vez que diminui as chances de haver comportamentos oportunistas, da incorporação de conhecimento de forma unilateral e do roubo de informações (Kale, Singh, \& Perlmutter, 2000).

O artigo seminal sobre capacidade relacional foi desenvolvido por Dyer e Singh (1998) em que a pesquisa apresentou que por meio da capacidade relacional era possível a geração de rendas relacionais, combinando recursos complementares, compartilhando conhecimentos com os parceiros de alianças. Definições similares e complementares foram sendo apresentadadas ao longo do tempo pela literatura, como de Donada, Nogatchewsky e Pezet (2015, p. 3) que apresenta a CR como "capacidade de integrar, construir e reconfigurar um conjunto de habilidades, ativos e rotinas que fornecem os recursos base para lidar com a mudança do ambiente", ou ainda, competências técnicas e interpessoais, que são utilizadas no gerenciamento das parcerias (Costa, Porto e Silva, 2012).

Neste estudo, a capacidade relacional será investigada a partir da perspectiva da capacidade dinâmica, em alianças díades, definida como aquela que uma organização possui intencionalmente, a fim de criar, expandir ou transformar a base de recursos, por meio de rotinas organizacionais (Helfat et al., 2009), isto é, de comportamentos aprendidos e repetidos ao longo do tempo (Winter, 2003).

Schilke e Goerzen (2010) desenvolveram um modelo multidimensional, baseado em rotinas e processos corporativos, dividido em cinco dimensões, mas que para esse estudo apenas quatro serão consideradas: coordenação interorganizacional, transformação da aliança, aprendizagem interorganizacional, proatividade em alianças.

A coordenação interorganizacional está relacionada às rotinas e processos que possibilitam governar a aliança de forma eficiente (Kumar \& Nti, 1998); a aprendizagem organizacional refere-se à capacidade que a empresa possui em obter, integrar, transformar e explorar os recursos provenientes da aliança, a fim de aprimorar o desempenho no mercado (Zahra \& George, 2002); a proatividade diz respeito às rotinas e processos que levam a empresa a tomar a iniciativa de formar alianças, identificando parceiros em potencial para complementação de recursos (Sarkar, Aulakh, \& Madhok, 2009); a transformação das alianças refere-se a rotinas e processos que contribuem para a realização de modificações na aliança e de ajustes necessários à potencialização de seu desempenho (Kale et al., 2002).

Schilke e Goerzen (2010) ainda apresentam em seu modelo dois fatores que influenciam a capacidade relacional: a experiência e a estrutura de governança. A experiência prévia, acumulada pela formação de alianças estratégicas anteriores, possibilita às organizações o desenvolvimento da habilidade de escolher parceiros em potencial, a fim de complementar recursos, gerenciar (Heimeriks \& Duysters, 2007; Kale \& Singh, 2007) e realizar ajustes, quando necessários (Heimeriks, Duysters, \& Vanhaverbeke, 2007). Empresas que detêm uma estrutura de governança voltada à administração das 
alianças, conseguem desenvolver meios para geri-las de forma mais eficiente (Heimeriks \& Duysters, 2007; Kale \& Singh, 2007).

Em recente estudo, Niesten e Jolink (2015) dividiram a CR em quatro categorias: CR geral, em nível interno da empresa; CR específica de um parceiro, em nível interno da empresa; CR geral, em nível da aliança; e CR específica de um parceiro, em nível da aliança. A CR geral é adquirida por meio da experiência com diferentes parceiros e que pode ser aplicada a diferentes tipos de alianças e parceiros de distinta natureza (Al-Laham, Amburgey, \& Bates, 2008). Já a CR específica é obtida de determinado parceiro e utilizada somente com o mesmo parceiro, em alianças atuais ou futuras (Al-Laham et al., 2008). Quanto ao contexto, existem elementos que podem ser capturados, divididos e armazenados, em nível da empresa (exclusivamente dentro da empresa) e em nível da aliança (Ritala, Armila, \& Blomqvist, 2009), conforme apresentado na Figura 3.

\section{Figura 3 - Classificação dos elementos para a capacidade relacional}

1. CR Geral (Dentro da empresa)
- Estruturas: escritório corporativo da aliança; vice-
presidente ou diretor da aliança; equipe da aliança; gestor da
aliança; responsável pela aliança; especialista na aliança;
comissões de aliança; força tarefa; porta-voz.
- Processos: relatórios de gerentes da aliança; registros e
relatórios sobre incidentes, decisões e desempenho das
alianças; mudança de gestores das alianças; recompensas
para gestores das alianças; fóruns e redes para intercâmbio
(in) formal de conhecimentos; treinamento interno da
aliança; seminários e workshops de alianças; avaliações
individuais e de alianças cruzadas.
- Ferramentas: diretrizes da aliança; fichas de trabalho;
manuais; lista de verificação; métricas; modelos para seleção
de parceiros, negociação e contratos das alianças;
ferramentas de avaliação dos parceiros; base de dados com
informações factuais sobre as alianças; simulações; diário;
lista de contatos; intranet.

\section{CR Geral (Dentro da aliança)}

- Estruturas: gestor da aliança, especialista em alianças ou sistema de comunicação na joint venture; equipes conjuntas de parceiros da aliança; comitê de revisão da aliança; equipe de gerenciamento interempresarial.

- Processos: treinamento de aliança externa; utilização de especialistas externos à aliança: consultores, advogados, mediadores e peritos financeiros; planejamento conjunto de negócios; avaliação conjunta; eventos de reunião no programa parceiro.

- Ferramentas: contrato de aliança como repositório do conhecimento da aliança; intranet compartilhada; sala de equipe virtual; diretório com detalhes de contato e repositório com documentos de aliança.

\section{CR Parceiro Específico (Dentro da empresa)}

- Estruturas: escritório de gestão da aliança; diretor de aliança; gestor da aliança; capacidade da empresa de fazer acordo com parceiro específico da aliança.

- Processos: processos informais e formais de partilha de conhecimentos sobre o parceiro da aliança; sessões de brainstorming; treinamento interno de aliança.

- Ferramentas: banco de dados com informações factuais sobre parceiros de alianças; intranet; manuais de implementação.

\section{CR Parceiro Específico (Dentro da aliança)}

- Estruturas: comitê de revisão da aliança; equipes conjuntas dos parceiros da aliança; canais de comunicação; interfaces com parceiros específicos; especialista em joint venture; grupo de trabalho entre empresas.

Processos: rotinas para compartilhamento de conhecimento específico entre empresa com um parceiro específico; planejamento conjunto de negócios; avaliação de aliança em conjunto; programa parceiro; discussão compartilhada da estratégia; reunião de desenvolvimento de processo.

- Ferramentas: memorando de entendimento; contrato de aliança como repositório de conhecimento de aliança; sala virtual e web-conferência da equipe; diretório com detalhes de contato e repositório com documentos da aliança; matriz de comunicações; intranet compartilhada.

Fonte: Niesten e Jolink, A. (2015). 
Cada categoria apresentada na figura anterior é dividida em três tipos: a) estrutura da aliança: formada pelas unidades organizacionais e de relacionamento (Heimeriks et al., 2007; Kale, Dyer, \& Singh, 2001; Heimeriks et al. 2007; Kale et al. 2001); b) processos da aliança: formados por mecanismos que contribuem para a captação do conhecimento e estimulam o compartilhamento de conhecimento entre parceiros e empregados (Kale \& Singh, 2007) e; c) ferramentas da aliança: que auxiliam na captação, compartilhamento, armazenamento e na aplicação do conhecimento codificado das alianças (Kale \& Singh, 2007, 2009).

Na primeira categoria, aos elementos, recursos e conhecimentos que auxiliam na reflexão sobre as experiências em alianças passadas (Hoang \& Rothaermel, 2005), pode-se incluir a criação de departamentos que supervisionem os gestores de alianças de diferentes departamentos da empresa (Hoffmann, 2005; Kale et al., 2001); em empresas pequenas, pode ser pela designação de um especialista para gerenciar o conhecimento de alianças (Draulans et al., 2003), ou ainda, manter uma base de dados com informações e histórico de cada uma das alianças (Kale \& Singh, 2007).

A segunda categoria está relacionada ao fato de que, muitas vezes, departamentos alternados dentro de uma empresa podem estar envolvidos em diferentes alianças, com um mesmo parceiro, assim, é importante que o conhecimento de cada aliança seja transferido de um departamento para outro (Pangarkar, 2009). Com isso, é possível que, em futuras alianças, com os parceiros repetidos, contratos mais detalhados e com custos menores sejam elaborados, em virtude das informações precisas obtidas sobre o parceiro (Ryall \& Sampson, 2006).

$\mathrm{Na}$ terceira categoria, encontram-se os elementos que são capturados, compartilhados, armazenados e aplicados na aliança, ao invés de internalizados na empresa. Entre os mecanismos, podem estar: a criação de um comitê ou equipe para auxiliar na gestão de alianças (Kale \& Singh, 2009; Schreiner et al., 2009); contratação de especialista para auxiliar na estruturação de uma joint venture; contratação de diferentes especialistas que, por meio de conhecimentos externos (Heimeriks \& Duysters, 2007; Heimeriks et al., 2009; Sluyts, Martens, \& Matthyssens, 2010), possam auxiliar nas distintas fases da aliança (Kale \& Singh, 2009).

$\mathrm{Na}$ quarta categoria, os parceiros que formam alianças repetidas captam conhecimentos recíprocos, mas de maneiras distintas. Conhecimentos, estruturas, canais de comunicação, equipes e rotinas desenvolvidos em determinada aliança podem ser utilizados no caso de futuras alianças com o mesmo parceiro (Hoang \& Rothaermel, 2005; Kale \& Singh, 2007).

Em recentes pesquisas, Alves (2015) reorganizou e agrupou, por semelhança, as dimensões de capacidades relacionais, a partir de cinco estudos, bem como desenvolveu novas dimensões do constructo (coordenação, cultura, conhecimento, tecnologia e coadaptação). A dimensão de coordenação está relacionada à capacidade de gestão da parceria, uma vez que administra os recursos, de modo a torná-la mais eficiente, lucrativa, geradora de produção e, com base no estudo de Schilke e 
Goerzen (2010), capaz de evitar a duplicação de atividades e de reduzir conflitos. A dimensão cultural se refere à capacidade da empresa em se relacionar com parceiros de diferentes culturas, lidando adequadamente com questões emocionais, sociais e conflitos que, eventualmente, possam surgir (Ngugi, Johnsen, \& Erdélyi, 2010). A terceira dimensão é a do conhecimento, relacionada à capacidade de gerar, incorporar, usar e administrar os saberes advindos da parceria. Ressalta-se, nessa dimensão, a questão da aprendizagem e das rotinas e processos presentes na transferência e resultados do conhecimento (Johnsen \& Ford, 2006; McGrath, 2008; Ngugi et al., 2010; Schilke \& Goerzen, 2010). A dimensão tecnológica reúne a coinovação (McGrath, 2008) e a tecnologia (Johnsen \& Ford, 2006; Ngugi et al., 2010), que se referem à competência de desenvolvimento, integração, expansão, inovação tecnológica e absorção do conhecimento dos parceiros. A quinta e última dimensão é a de coadaptação que está voltada à capacidade de adequar recursos ou meios de funcionamento, em função de ampliar os benefícios da parceria, seja por meio da criação de novos produtos ou soluções, seja por relacionamentos mais adequados (McGrath, 2008; Sarkar et al., 2009; Schilke \& Goerzen, 2010).

O gerenciamento de uma aliança demanda capacidades relacionais que nem sempre são fáceis de adquirir e manter (Ireland, Hitt, \& Vaidyanath, 2002). Donada et al. (2015) realizaram estudo longitudinal, buscando compreender como a capacidade é construída e de que maneira é capaz de evoluir em um ambiente de mudança, ao longo do tempo. Os autores encontraram três fases, avaliadas conforme consta na Figura 4.

Figura 4 - Fases da construção e evolução da capacidade relacional

FASE 1

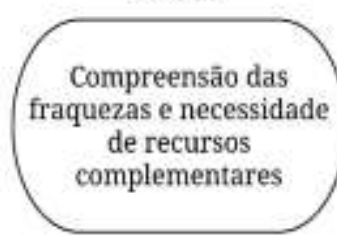

FASE 2

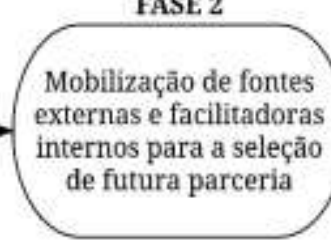

FASE 3

Integração das habilidades, ativos $\mathrm{e}$ rotinas resultantes da aliança, para que possam. ser aplicadas a prática

Fonte: Adaptado de Donada, Nogatchewsky e Pezet, A. (2015).

A primeira delas é quando a empresa compreende suas fraquezas e percebe a necessidade de recursos complementares, estímulo esse gerado, normalmente, por fatores externos. Assim, desenvolve-se um período de aprendizagem e de análise do conhecimento interno, visto que ainda não estão estabelecidas as intenções estratégicas a serem utilizadas (Donada et al., 2015). A segunda fase é mais operacional, pois há uma mobilização de fontes externas e facilitadores internos, de modo a desenvolver e coordenar as capacidades relacionais para a avaliação e seleção de futuros parceiros (Donada et al., 2015). Por fim, a terceira fase é mais estratégica, já que é o momento do surgimento das 
primeiras rendas relacionais e da realização das projeções de longo prazo. Nessa fase, os facilitadores internos desempenham uma papel importante, visando integrar as habilidades, ativos e rotinas resultantes da aliança à estratégia da empresa, a fim de que sejam aplicados, na prática, para constituir uma governança relacional eficaz (Donada et al., 2015).

Por fim, pode-se sintetizar que em decorrência da dificuldade de promover, isoladamente, inovações, e a fim de alcançar maior competitividade, crescimento (Dyer \& Singh, 1998, e versatilidade (Ding, Dekker, \& Groot, 2013; Rothaermel, Hitt, \& Jobe, 2006), as alianças estratégicas têm sido consideradas uma alternativa, nas últimas décadas, às empresas, haja vista a possibilidade de complementação de recursos (Dyer \& Singh, 1998), acesso a novos mercados e redução de custos (Ahuja, 2000). O estudo das alianças estratégicas é, portanto, um assunto de relevância, por isso foi estudado neste trabalho.

Formadas entre atores de diferente natureza, como universidades, empresas privadas, públicas, concorrentes, clientes, fornecedores, institutos de pesquisa públicos ou privados, essas alianças estratégicas podem ter finalidades distintas, como P\&D, transferência de tecnologia, cooperação em marketing etc. (Möller \& Halinen, 1999). Entretanto, a formação de alianças não é um processo simples, pois nem sempre é possível alcançar os objetivos para os quais elas foram propostas.

As chances de um desempenho satisfatório de uma aliança aumentam, se as instituições envolvidas desenvolverem a capacidade de trocar, continuamente, informações e conhecimentos com os parceiros, de criar estruturas para a gestão das alianças, gerenciar conflitos e estabelecer confiança mútua (Yan, Zhang, \& Zeng, 2010). Ou ainda, a capacidade de criar mecanismos de proteção de ativos, diminuindo assim, as chances de haver comportamentos oportunistas, a incorporação de conhecimento de forma unilateral e o roubo de informações (Kale, Singh, \& Perlmutter, 2000). Essa capacidade, quando desenvolvida, é denominada capacidade relacional (Schilke \& Goerzen, 2010).

Sendo assim, a capacidade relacional pode ser investigada a partir da perspectiva da capacidade dinâmica, em que uma instituição busca por meio de rotinas organizacionais (Helfat et al., 2009), isto é, de comportamentos aprendidos e repetidos ao longo do tempo (Winter, 2003), criar, expandir ou transformar a base de recursos (Helfat et al., 2009). Sobre a instrumentalização da capacidade relacional, descata-se o modelo de Schilke e Goerzen (2010), composto por uma construção multidimensional, baseada em rotinas e processos corporativos, dividida em cinco dimensões: coordenação interorganizacional, transformação da aliança, aprendizagem, proatividade em alianças e portfólio de alianças. Destaca-se ainda neste modelo multidimensional os fatores que influenciam a capacidade relacional: a experiência e a estrutura da aliança (Schilke \& Gorzen, 2010).

A experiência prévia, acumulada pela formação de alianças estratégicas anteriores, possibilita às organizações o desenvolvimento da habilidade de escolher parceiros em potencial, a fim de complementar os recursos, gerenciar (Heimeriks \& Duysters, 2007; Kale \& Singh, 2007) e realizar 
ajustes, quando necessários (Heimeriks, Duysters, \& Vanhaverbeke, 2007). Empresas que detêm uma estrutura de aliança voltada à administração das alianças, conseguem centralizar as informações, facilitar a comunicação entre os setores (Hoang \& Rothaermel, 2005), desenvolvendo meios para gerir as alianças de forma mais eficiente (Heimeriks \& Duysters, 2007; Kale \& Singh, 2007). Sobre a estrutura da aliança, destaca-se a formalização da governança, ou seja, os diferentes níveis de formalização de uma aliança relacionados aos mecanismos de proteção de propriedade intelectual (Faems, Van Looy, \& Debackere, 2005), considerando os parceiros e objetos das alianças.

\section{Proposição de um modelo conceitual}

Nessa seção, busca-se esquematizar, a partir de um mapa conceitual, os principais pontos abordados na fundamentação teórica. Em linhas gerais, propõe-se que, quando uma organização possui capacidade relacional, são maiores as possibilidades de geração de inovações e de transbordamento da capacidade relacional para os parcerios envolvidos. Apresenta-se assim, as proposições formuladas com relação as dimensões da CR e os fatores que influenciam a CR, de acordo com a natureza da instituição, bem como suas conexões com o mercado.

A literatura aponta que, empresas que têm departamentos e pessoas específicas para o gerenciamento das alianças, conseguem aumentar seu desempenho (Heimeriks \& Duysters, 2007; Kale \& Singh, 2007), isso porque, a partir de uma estrutura formalizada e da experiência que vai se adquirindo (Sluyts, Matthyssens, Martens, \& Streukens, 2011), é possível desenvolver mecanismos, procedimentos, ferramentas e treinamentos adequados para a gestão da aliança (Heimeriks \& Duysters, 2007; Kale \& Singh, 2007). Além disso, há maior capacidade para elaborar e celebrar contratos, cujas cláusulas e acordos auxiliam na prevenção de riscos e de oportunismos futuros (Argyres \& Mayer, 2007). Considerase assim, que a formalização da estrutura de governança de uma aliança, ou seja, o nível de formalização dos contratos, que inclui os instrumentos de controle, cláusulas de propriedade, ou a exigência de documentação para a celebração da aliança é relevante à capacidade relacional, podendo no entanto, variar de acordo com o propósito da aliança (pesquisa ou desenvolvimento) e o perfil do parceiro (conectado e não conectado ao mercado) (Lin \& Darnall, 2015).

Assim, nesse estudo, tem-se a expectativa de que sejam adotados instrumentos de curto e médio prazo e cláusulas de propriedade mais formais, quando o propósito é o desenvolvimento de soluções imediatas para o mercado, envolvendo a aplicação de tecnologias protegidas (Lhuillery \& Pfister, 2009) e organizações conectadas ao mercado com maior expertise em desenvolvimento de produtos e processos (Jap \& Anderson, 2003; Williamson, 1985). Já, nas alianças estabelecidas com organizações não conectadas diretamente ao mercado, e com expertise em pesquisa (universidades públicas, institutos de pesquisa públicos e organizações sociais), espera-se que sejam adotados 
instrumentos de longo prazo e cláusulas de propriedade menos formais, uma vez que os propósitos são o avanço e a disseminação do conhecimento científico e/ou social, a partir de pesquisa básica e/ou aplicada (Lhuillery \& Pfister, 2009; Martin, 2012). Assim, é possível estabelecer as seguintes proposições:

Proposição 1: A formalização da estrutura de governança tende a ser maior quando se estabelece alianças estratégicas entre instituições de pesquisa públicas e organizações conectadas ao mercado.

Proposição 2: A formalização da estrutura de governança tende a ser menor quando se estabelece aliança estratégica entre instituições de pesquisa públicas e organizações não conectadas ao mercado.

Proposição 3: A formalização da estrutura de governança tende a ser maior quando o propósito da aliança está relacionado ao desenvolvimento de curto ou médio prazo.

Proposição 4: A formalização da estrutura de governança tende a ser menor quando o propósito da aliança está relacionado à pesquisa de longo prazo.

A experiência acumulada em alianças estratégicas anteriores faz com que as empresas desenvolvam a capacidade de selecionar parceiros, administrar as alianças, (Heimeriks \& Duysters, 2007; Kale \& Singh, 2007) e realizar as adaptações necessárias (Heimeriks et al., 2007). De forma específica, há maior sensibilidade na prospecção de informações e conhecimentos de múltiplas fontes externas. Sendo assim, tem-se a expectativa de que a variação de parceiros pode ser oportuna em alianças relacionadas à pesquisa de longo prazo, de novos conhecimentos, em prol do avanço da ciência e da sociedade como um todo. Ademais, a repetição de parceiros na formação de alianças gera, também, maior agilidade na condução de rotinas e processos, pois permite maior conhecimento sobre cultura, crenças e forma de atuação do parceiro, facilitando o gerenciamento da parceria e aumentando as chances de sua eficácia (Zollo et al., 2002; Khanna, Gulati, \& Nohria, 1998). Acredita-se, portanto, que a repetição de parceiros pode ser oportuna em alianças relacionadas ao desenvolvimento de soluções imediatas para o mercado. Assim, são estabelecidas as seguintes proposições:

Proposição 5: Quando o propósito é a pesquisa de longo prazo, a experiência no estabelecimento de alianças estratégicas, com diferentes parceiros, potencializa a capacidade relacional. 
Proposição 6: Quando o propósito é o desenvolvimento de curto e médio prazo, a experiência no estabelecimento de alianças estratégicas, com os mesmos parceiros, potencializa a capacidade relacional.

Institutos de pesquisa (não conectados ao mercado) são considerados importantes fontes de pesquisa, desenvolvimento e inovação, já que cada um deles objetiva a realização de pesquisas para desenvolvimento de novos conhecimentos e tecnologias em áreas específicas, dando, ainda, sustentação à promoção de inovações (Sousa et al., 2005). Por outro lado, instituições conectadas ao mercado pelo fato de estarem interligadas com a prática, cabe a elas a responsabilidade de colocar essas inovações no mercado (Lundvall, 1988). Considerando essa lógica, tem-se a expectativa de que, em alianças de P\&D haja o transbordamento de rotinas e processos de uma instituição para a outra, ou seja, as instituições institucionalizam e, posteriormente, transferem rotina(s) e/ou processo(s) inerentes às atividades de pesquisa (do instituto de pesquisa não conectado ao mercado, para parceiros conectados ou não conectados) e de desenvolvimento (dos parceiros conectados ou não ao mercado, para o instituto de pesquisa não conectado ao mercado), resultando em aprimoramento ou novas práticas. Assim, propõe-se que:

Proposição 7: Em alianças estratégicas de P\&D, rotinas e processos inerentes à pesquisa são transbordados do instituto de pesquisa (não conectado ao mercado) para parceiros (conectados ou não conectados).

Proposição 8: Em alianças estratégicas de P\&D, rotinas e processos inerentes ao desenvolvimento são transbordados dos parceiros (conectados ou não conectados ao mercado) para o instituto de pesquisa (não conectado ao mercado).

Schilke e Goerzan (2010) definiram que a capacidade relacional é dimensionada por rotinas e processos, presentes nas seguintes dimensões: coordenação interorganizacional, aprendizagem interorganizacional, proatividade em aliança e transformação da aliança. A coordenação interorganizacional está relacionada às rotinas e processos que possibilitam governar a aliança de forma eficiente (Kumar \& Nti, 1998); a aprendizagem organizacional refere-se à capacidade que a empresa possui em obter, integrar, transformar e explorar os recursos provenientes da aliança, a fim de aprimorar o desempenho no mercado (Zahra \& George, 2002); a proatividade diz respeito às rotinas e processos que levam a empresa a tomar a iniciativa de formar alianças, identificando parceiros em potencial para complementação de recursos (Sarkar et al., 2009); a transformação das alianças refere- 
se a rotinas e processos que contribuem para a realização de modificações na aliança e de ajustes necessários à potencialização de seu desempenho (Kale et al., 2002; Niederkofler, 1991).

Portanto, quando instituições possuem estruturas organizacionais estabelecidas e pessoas especializadas e comprometidas, de modo que produzam resultados favoráveis, as rotinas e os procedimentos de gestão das alianças estratégicas de P\&D são institucionalizados dentro da instituição (Crossan, Lane, \& White, 1999), tendo assim a expectativa de que tenha alcançado uma capacidade relacional amadurecida. Então, propõe-se que:

Proposição 9: À medida que as organizações institucionalizam as dimensões coordenação interorganizacional, proatividade em aliança, aprendizagem organizacional e transformação das alianças, mais madura será a capacidade relacional.

Assim, na Figura 5, é possível visualizar o Framework Conceitual, elaborado a partir das proposições, de acordo com a literatura. Vale exclarecer que o referido Framework é formado por quatro blocos de análise interdependentes, a saber:

- Na parte superior do Framework, constam os dois primeiros blocos de análise: Bloco 1 Experiência em alianças, fundamentado pelas proposições 5 e 6, e Bloco 2 - Transbordamento de rotinas e processos de P\&D, sustetado pelas proposições 7 e 8 .

- Já na parte inferior do Framework, constam os dois últimos blocos de análise: Bloco 3 Formalização e Estrutura de Governança, fundamentado pelas proposições 1, 2, 3 e 4, e Bloco 4 - Institucionalização e Amadurecimentos, sustetando pela proposição 9. 
Figura 5 - Framework Conceitual do Estudo

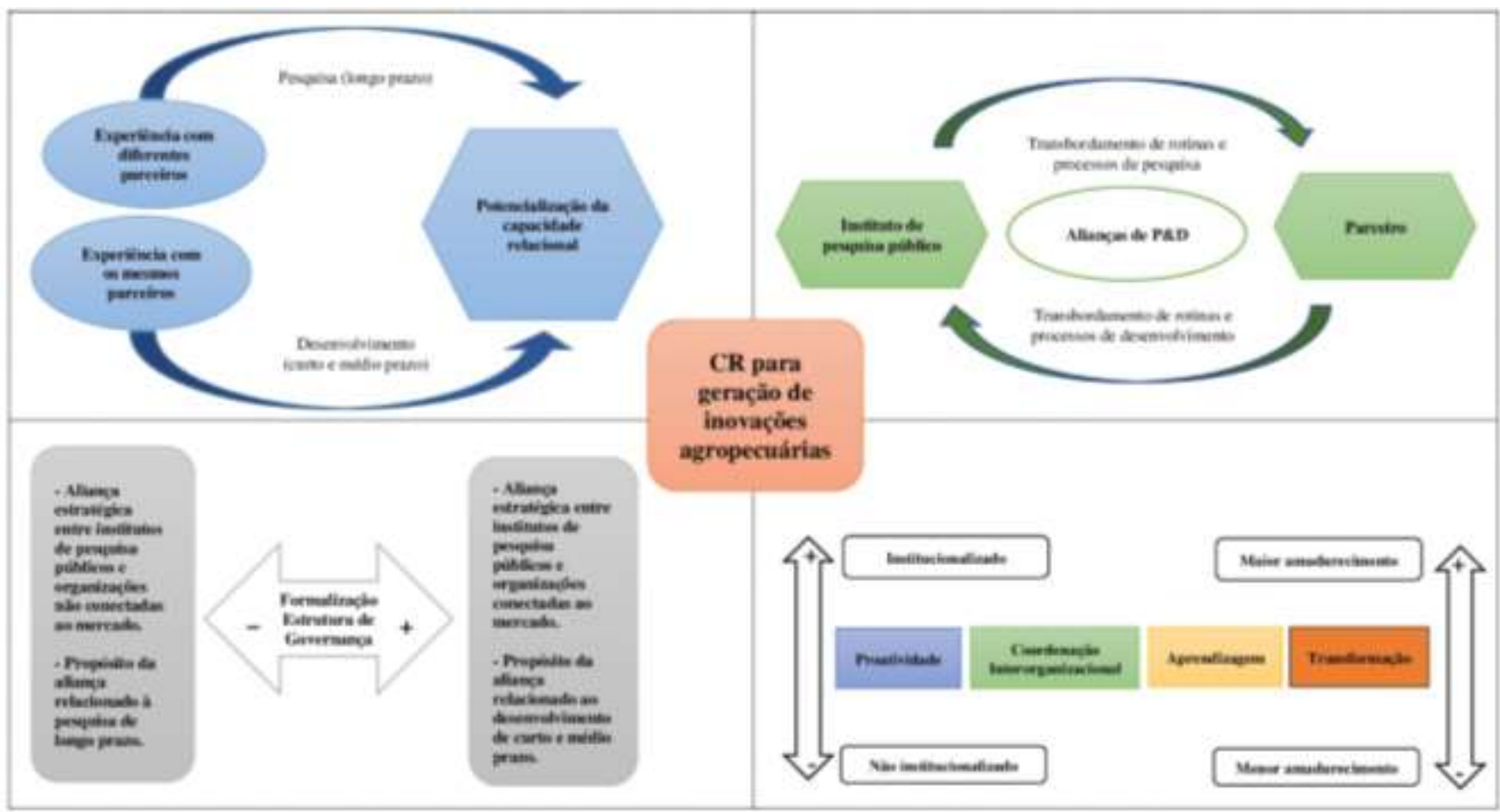

Fonte: Elaborado pelos autores.

\section{Considerações finais}

Por meio deste ensaio teórico exploratório foi possível desenvolver um modelo de geração de inovações no contexto de alianças estratégicas por meio da capacidade relacional. As proposições apresentadas, foram elaboradas a partir das dimensões e fatores influenciadores da CR com base no estudo de Schilke e Goerzen (2010). Assim, este ensaio ofereceu contribuições ao campo conceitual da CR quando se trata da formação de alianças entre instituições de natureza distintas (conexão com o mercado) e de acordo com o objetivo da aliança, para pesquisa ou desenvolvimento. A limitação desse estudo está relacionada quanto a delimitação do objeto das alianças (P\&D). Assim, estudos futuros poderão ser realizados investigando as dimensões e fatores da CR, em alianças que com objetivos distintos de P\&D.

\section{Referências}

Ahuja, G. (2000). Collaboration networks, structural holes, and innovation: A longitudinal study. Administrative Science Quarterly, 45(3), 425-455.

Al-Laham, A., Amburgey, T. L., \& Bates, K. (2008). The dynamics of research alliances: examining the effect of alliance experience and partner characteristics on the speed of alliance entry in the biotech industry. British Journal of Management, 19(4), 343-364. 
Alves, F. S. (2015). Capacidades relacionais em cooperações para desenvolvimento de tecnologias com e sem fins lucrativos. Recuperado de http://acervodigital.ufpr.br/handle/1884/39991

Argyres, N., \& Mayer, K. J. (2007). Contract design as a firm capability: An integration of learning and transaction cost perspectives. Academy of Management Review, 32(4), 1060-1077.

Arino, A., \& De La Torre, J. (1998). Learning from failure: Towards an evolutionary model of collaborative ventures. Organization Science, 9(3), 306-325.

Barney, J. (1991). Firm resources and sustained competitive advantage. Journal of Management, 17(1), 99-120.

Barringer, B. R., \& Harrison, J. S. (2000). Walking a tightrope: Creating value through interorganizational relationships. Journal of Management, 26(3), 367-403.

Cannon, J. P., \& Homburg, C. (2001). Buyer-supplier relationships and customer firm costs. Journal of Marketing, 65(1), 29-43.

Capaldo, A., \& Messeni Petruzzelli, A. (2011). In search of alliance-level relational capabilities: Balancing innovation value creation and appropriability in R\&D alliances. Scandinavian Journal of Management, 27(3), 273-286.

Chesbrough, H. (2006). Open innovation: a new paradigm for understanding industrial innovation. Open innovation: Researching a new paradigm, 1-12.

Christmann, P. (2000). Effects of "best practices" of environmental management on cost advantage: The role of complementary assets. Academy of Management journal, 43(4), 663-680.

Costa, P. R. da, Porto, G. S., \& Silva, A. T. B. da. (2012). Capacidades dinâmicas de inovação e cooperação: aspectos da trajetória e da maturidade das multinacionais brasileiras. In XV SEMEAD. São Paulo.

Cyert, R. M., \& Goodman, P. S. (1997). Creating effective university-industry alliances: An organizational learning perspective. Organizational dynamics, 25(4), 45-57.

Czakon, W. (2009). Relational Capability of Organizations-Theoretical Advances. Journal of Economics and Managment, 5, 47-65.

Dacin, M. T., Oliver, C., \& Roy, J.-P. (2007). The legitimacy of strategic alliances: An institutional perspective. Strategic Management Journal, 28(2), 169-187.

Darnall, N., \& Edwards, D. (2006). Predicting the cost of environmental management system adoption: the role of capabilities, resources and ownership structure. Strategic Management Journal, 27(4), 301-320.

Das, T. K., \& Teng, B.-S. (2000). A resource-based theory of strategic alliances. Journal of Management, 26(1), 31-61.

Delbufalo, E., \& Cerruti, C. (2012). Configuration and the capability of firms to innovate: A theoretical framework. International Journal of Management, 29(3), 16. 
Delmas, M., \& Toffel, M. W. (2004). Stakeholders and environmental management practices: an institutional framework. Business strategy and the Environment, 13(4), 209-222.

DiMaggio, P. J., \& Powell, W. W. (1983). The iron cage revisited: Institutional isomorphism and collective rationality in organizational fields. American Sociological Review, 48(2), 147-160.

Ding, R., Dekker, H. C., \& Groot, T. (2013). Risk, partner selection and contractual control in interfirm relationships. Management Accounting Research, 24(2), 140-155.

Donada, C. (2002). Generating cooperative gain in a vertical partnership: A supplier's perspective. Canadian Journal of Administrative Sciences/Revue Canadienne des Sciences de l'Administration, 19(2), 173-183.

Donada, C., Nogatchewsky, G., \& Pezet, A. (2015). Understanding the relational dynamic capabilitybuilding process. Strategic Organization, 14(2), 93-117.

Draulans, J., Volberda, H. W., \& others. (2003). Building alliance capability: Management techniques for superior alliance performance. Long range planning, 36(2), 151-166.

Dussauge, P., \& Garrette, B. (1995). Determinants of success in international strategic alliances: Evidence from the global aerospace industry. Journal of International Business Studies, 26(3), 505530.

Dyer, J. H. (1997). Effective interfirm collaboration: how firms minimize transaction costs and maximize transaction value. Strategic Management Journal, 535-556.

Dyer, J. H., \& Singh, H. (1998). The relational view: Cooperative strategy and sources of interorganizational competitive advantage. Academy of management review, 23(4), 660-679.

Etzion, D. (2007). Research on organizations and the natural environment, 1992-present: A review. Journal of Management, 33(4), 637-664.

Etzkowitz, H. (2003). Research groups as "quasi-firms": the invention of the entrepreneurial university. Research policy, 32(1), 109-121.

Faems, D., Van Looy, B., \& Debackere, K. (2005). Interorganizational collaboration and innovation: toward a portfolio approach. Journal of product innovation management, 22(3), 238-250.

Feller, J., Parhankangas, A., Smeds, R., \& Jaatinen, M. (2013). How companies learn to collaborate: Emergence of improved inter-organizational processes in R\&D alliances. Organization Studies, 34(3), 313-343.

Freitas, I. M. B., Marques, R. A., \& Silva, E. M. de P. e. (2013). University-industry collaboration and innovation in emergent and mature industries in new industrialized countries. Research Policy, 42(2), 443-453.

Gil, A. C.(2002). Como elaborar projetos de pesquisa ( $4^{\circ}$ ed). São Paulo: Atlas.

Granovetter, M. S. (1973). The strength of weak ties. American journal of sociology, 1360-1380.

Grant, R. M. (1991). The resource-based theory of competitive advantage: implications for strategy formulation. California management review, 33(3), 114-135. 
Gulati, R. (1995a). Does familiarity breed trust? The implications of repeated ties for contractual choice in alliances. Academy of management journal, 38(1), 85-112.

Gulati, R. (1995b). Social structure and alliance formation patterns: A longitudinal analysis. Administrative Science Quarterly, 619-652.

Gulati, R. (1998). Alliances and networks. Strategic Management Journal, 19(4), 293-317.

Hagedoorn, J., \& Narula, R. (1996). Choosing organizational modes of strategic technology partnering: international and sectoral differences. Journal of international business studies, 27(2), 265-284.

Hamel, G. (1991). Competition for competence and interpartner learning within international strategic alliances. Strategic Management Journal, 12(S1), 83-103.

Heimeriks, K. H., \& Duysters, G. (2007). Alliance capability as a mediator between experience and alliance performance: an empirical investigation into the alliance capability development process. Journal of Management Studies, 44(1), 25-49.

Heimeriks, K. H., Duysters, G., \& Vanhaverbeke, W. (2007). Learning mechanisms and differential performance in alliance portfolios. Strategic Organization, 5(4), 373-408.

Heimeriks, K. H., Klijn, E., \& Reuer, J. J. (2009). Building capabilities for alliance portfolios. Long Range Planning, 42(1), 96-114.

Helfat, C. E., Finkelstein, S., Mitchell, W., Peteraf, M., Singh, H., Teece, D., \& Winter, S. G. (2009). Dynamic capabilities: Understanding strategic change in organizations. John Wiley \& Sons.

Hitt, M. A., Ireland, R. D., \& Lee, H. (2000). Technological learning, knowledge management, firm growth and performance: an introductory essay. Journal of Engineering and Technology Management, 17(3-4), 231-246.

Hoang, H., \& Rothaermel, F. T. (2005). The effect of general and partner-specific alliance experience on joint R\&D project performance. Academy of Management Journal, 48(2), 332-345.

Hoffmann, W. H. (2005). How to manage a portfolio of alliances. Long Range Planning, 38(2), $121-$ 143.

Ireland, R. D., \& Webb, J. W. (2007). Strategic entrepreneurship: Creating competitive advantage through streams of innovation. Business Horizons, 50(1), 49-59.

Ireland, R. D., Hitt, M. A., \& Vaidyanath, D. (2002). Alliance management as a source of competitive advantage. Journal of management, 28(3), 413-446.

Jap, S. D. (2001). "Pie sharing" in complex collaboration contexts. Journal of Marketing Research, 38(1), 86-99.

Jap, S. D., \& Anderson, E. (2003). Safeguarding interorganizational performance and continuity under ex post opportunism. Management Science, 49(12), 1684-1701.

Johnsen, R. E., \& Ford, D. (2006). Interaction capability development of smaller suppliers in relationships with larger customers. Industrial Marketing Management, 35(8), 1002-1015. 
Jones, C., Hesterly, W. S., \& Borgatti, S. P. (1997). A general theory of network governance: Exchange conditions and social mechanisms. Academy of management review, 22(4), 911-945.

Kale, P., \& Singh, H. (2007). Building firm capabilities through learning: the role of the alliance learning process in alliance capability and firm-level alliance success. Strategic Management Journal, 28(10), 981-1000.

Kale, P., \& Singh, H. (2009). Managing strategic alliances: What do we know now, and where do we go from here. Academy of management perspectives, 23(3), 45-62.

Kale, P., Dyer, J. H., \& Singh, H. (2002). Alliance capability, stock market response, and long-term alliance success: the role of the alliance function. Strategic Management Journal, 23(8), 747-767.

Kale, P., Dyer, J., \& Singh, H. (2001). Value creation and success in strategic alliances:: alliancing skills and the role of alliance structure and systems. European Management Journal, 19(5), 463-471.

Kale, P., Singh, H., \& Perlmutter, H. (2000). Learning and protection of proprietary assets in strategic alliances: Building relational capital. Strategic Management Journal, 21(3), 217-237.

Kalwani, M. U., \& Narayandas, N. (1995). Long-term manufacturer-supplier relationships: do they pay off for supplier firms? The Journal of marketing, 59, 1-16.

Khanna, T., Gulati, R., \& Nohria, N. (1998). The dynamics of learning alliances: Competition, cooperation, and relative scope. Strategic Management Journal, 19(3), 193-210.

Kogut, B. (1988). Joint ventures: Theoretical and empirical perspectives. Strategic Management Journal, 9(4), 319-332.

Kok, R. A., \& Creemers, P. A. (2008). Alliance governance and product innovation project decision making. European Journal of Innovation Management, 11(4), 472-487.

Koza, M. P., \& Lewin, A. Y. (1998). The co-evolution of strategic alliances. Organization science, 9(3), 255-264.

Kumar, R., \& Nti, K. O. (1998). Differential learning and interaction in alliance dynamics: A process and outcome discrepancy model. Organization science, 9(3), 356-367.

Lhuillery, S., \& Pfister, E. (2009). R\&D cooperation and failures in innovation projects: Empirical evidence from French CIS data. Research Policy, 38(1), 45-57.

Lin, H., \& Darnall, N. (2015). Strategic alliance formation and structural configuration. Journal of Business Ethics, 127(3), 549-564.

Lin, Z., Yang, H., \& Demirkan, I. (2007). The performance consequences of ambidexterity in strategic alliance formations: Empirical investigation and computational theorizing. Management Science, 53(10), 1645-1658.

Lundvall, B. A. (1988). Innovation as an interactive process: From user-producer interaction to the National System of Innovation (1988). G. Dosi, C. Freeman, R. Nelson, G. Silverberg \& L. Soete (Eds.). Technical change and economic theory. London: Pinter Publishers, chp, 11, 349-369. 
March, J. G. (1991). Exploration and exploitation in organizational learning. Organization science, 2(1), 71-87.

Martin, B. R. (2012). Are universities and university research under threat? Towards an evolutionary model of university speciation. Cambridge Journal of Economics, 36(3), 543-565.

McGrath, H. (2008). Developing a relational capability construct for SME network marketing using cases and evidence from Irish and Finnish SMEs. Waterford Institute of Technology, Irland.

Meyer, J. W., \& Rowan, B. (1977). Institutionalized organizations: Formal structure as myth and ceremony. American Journal of Sociology, 340-363.

Möller, K. K., \& Halinen, A. (1999). Business relationships and networks: Managerial challenge of network era. Industrial marketing management, 28(5), 413-427.

Narula, R., \& Hagedoorn, J. (1999). Innovating through strategic alliances: moving towards international partnerships and contractual agreements. Technovation, 19(5), 283-294.

Ngugi, I. K., Johnsen, R. E., \& Erdélyi, P. (2010). Relational capabilities for value co-creation and innovation in SMEs. Journal of Small Business and Enterprise Development, 17(2), 260-278.

Niederkofler, M. (1991). The evolution of strategic alliances: Opportunities for managerial influence. Journal of Business Venturing, 6(4), 237-257.

Niesten, E., \& Jolink, A. (2015). The impact of alliance management capabilities on alliance attributes and performance: a literature review. International Journal of Management Reviews, 17(1), 69-100.

Organização para Cooperação e Desenvolvimento Econômico - OCDE. (2005). Manual de Oslo: diretrizes para coleta e interpretação de dados sobre inovação.

Oliver, C. (1991). Strategic responses to institutional processes. Academy of Management Review, 16(1), 145-179.

Ostrom, E. (1998). A behavioral approach to the rational choice theory of collective action: Presidential address, American Political Science Association, 1997. American Political Science Review, 92(01), 1-22.

Pagano, A. (2009). The role of relational capabilities in the organization of international sourcing activities: A literature review. Industrial Marketing Management, 38(8), 903-913.

Pangarkar, N. (2009). Do firms learn from alliance terminations? An empirical examination. Journal of Management Studies, 46(6), 982-1004.

Park, S. H., Chen, R. R., \& Gallagher, S. (2002). Firm resources as moderators of the relationship between market growth and strategic alliances in semiconductor start-ups. Academy of Management Journal, 45(3), 527-545.

Philbin, S. P., Jones, D., Brandon, N. P., \& Hawkes, A. D. (2014). Exploring research institutes: Structures, functioning and typology. In Management of Engineering \& Technology (PICMET), 2014 Portland International Conference on (p. 2569-2582). IEEE. 
Powell, W. W. (1987). Hybrid organizational arrangements: new form or transitional development? California Management Review, 30(1), 67-87.

Powell, W. W., Koput, K. W., \& Smith-Doerr, L. (1996). Interorganizational collaboration and the locus of innovation: Networks of learning in biotechnology. Administrative Science Quarterly, 116-145.

Ring, P. S., \& Van de Ven, A. H. (1992). Structuring cooperative relationships between organizations. Strategic Management Journal, 13(7), 483-498.

Rodríguez-Díaz, M., \& Espino-Rodríguez, T. F. (2006). Redesigning the supply chain: reengineering, outsourcing, and relational capabilities. Business Process Management Journal, 12(4), 483-502.

Rothaermel, F. T., \& Deeds, D. L. (2004). Exploration and exploitation alliances in biotechnology: A system of new product development. Strategic Management Journal, 25(3), 201-221.

Ryall, M. D., \& Sampson, R. C. (2006). Do prior alliances influence alliance contract structure. In Strategic alliances (p. 206-216). Basingstoke: Palgrave Macmillan. Recuperado de http://citeseerx.ist.psu.edu/viewdoc/download?doi=10.1.1.488.9542\&rep=rep1\&type=pdf

Sarkar, M. B., Aulakh, P. S., \& Madhok, A. (2009). Process capabilities and value generation in alliance portfolios. Organization Science, 20(3), 583-600.

Schilke, O., \& Goerzen, A. (2010). Alliance management capability: an investigation of the construct and its measurement. Journal of Management, 36(5), 1192-1219.

Schreiner, M., Kale, P., \& Corsten, D. (2009). What really is alliance management capability and how does it impact alliance outcomes and success? Strategic Management Journal, 30(13), 1395-1419.

Schumpeter, J. A. (1934). The Theory of Economic Development: An Inquiry Into Profits, Capital, Credit, Interest, and the Business Cycle. Transaction Publishers.

Sluyts, K., Martens, R., \& Matthyssens, P. (2010). How to build alliance capability: A life cycle approach. In Enhancing Competences for Competitive Advantage (Vol. 12, p. 173-200). Emerald Group Publishing Limited.

Sluyts, K., Matthyssens, P., Martens, R., \& Streukens, S. (2011). Building capabilities to manage strategic alliances. Industrial Marketing Management, 40(6), 875-886.

Sousa, S. V. A., Langemann, L., \& Pitangueira, A. M. S. (2005). Institutos de pesquisa como agentes de desenvolvimento da indústria de tecnologia da informação. In $29^{\circ}$ Encontro da Associação Nacional de Programas de Pós-Graduação em Administração. São Paulo.

Teece, D. J., Pisano, G., Shuen, A., \& others. (1997). Dynamic capabilities and strategic management. Strategic Management Journal, 18(7), 509-533.

Walsh, J. P., Lee, Y.-N., \& Nagaoka, S. (2016). Openness and innovation in the US: Collaboration form, idea generation and implementation. Research Policy.

Wang, L., \& Zajac, E. J. (2007). Alliance or acquisition? A dyadic perspective on interfirm resource combinations. Strategic management journal, 28(13), 1291-1317. 
Williamson, O. E. (1985). The economic institutions of capitalism. Free Press, New York: Simon and Schuster.

Winter, S. G. (2003). Understanding dynamic capabilities. Strategic Management Journal, 24(10), 991995.

Winter, S. G., \& Nelson, R. R. (1982). An Evolutionary Theory of Economic Change (SSRN Scholarly Paper No. ID 1496211). Rochester, NY: Social Science Research Network.

Yan, Y., Zhang, S. H., \& Zeng, F. (2010). The exploitation of an international firm's relational capabilities: an empirical study. Journal of Strategic Marketing, 18(6), 473-487.

Zahra, S. A., \& George, G. (2002). Absorptive capacity: A review, reconceptualization, and extension. Academy of management review, 27(2), 185-203.

Zollo, M., \& Winter, S. G. (2002). Deliberate learning and the evolution of dynamic capabilities. Organization science, 13(3), 339-351. 